\title{
Influence of humic acid addition on the degradation of pharmaceuticals by biofilms in
} effluent wastewater

Tang, Kai; Escola Casas, Monica; Ooi, Gordon Tze Hoong; Kaarsholm, Kamilla Marie Speht; Bester, Kai; Andersen, Henrik Rasmus

Published in:

International Journal of Hygiene and Environmental Health

Link to article, DOI:

10.1016/j.ijheh.2017.01.003

Publication date:

2017

Document Version

Peer reviewed version

Link back to DTU Orbit

Citation (APA):

Tang, K., Escola Casas, M., Ooi, G. T. H., Kaarsholm, K. M. S., Bester, K., \& Andersen, H. R. (2017). Influence of humic acid addition on the degradation of pharmaceuticals by biofilms in effluent wastewater. International Journal of Hygiene and Environmental Health, 220(3), 604-610. https://doi.org/10.1016/j.ijheh.2017.01.003

\section{General rights}

Copyright and moral rights for the publications made accessible in the public portal are retained by the authors and/or other copyright owners and it is a condition of accessing publications that users recognise and abide by the legal requirements associated with these rights.

- Users may download and print one copy of any publication from the public portal for the purpose of private study or research.

- You may not further distribute the material or use it for any profit-making activity or commercial gain

- You may freely distribute the URL identifying the publication in the public portal 


\section{Influence of humic acid addition on the degradation of pharmaceuticals by biofilms in effluent wastewater}

Kai Tang ${ }^{1}$, Monica Escola Casas $^{2}$, Gordon T.H. Ooi ${ }^{1}$, Kamilla M. S. Kaarsholm ${ }^{1}$, Kai Bester ${ }^{2}$, Henrik R. Andersen ${ }^{1 *}$.

1) Department of Environmental Engineering, Technical University of Denmark, Bygningstorvet 115, 2800 Kgs. Lyngby, Denmark

${ }^{2)}$ Environmental Science, Århus University, Frederiksborgvej 399, 4000 Roskilde, Denmark.

*Corresponding author email: Henrik@,ndersen.net.

\section{Abstract}

The degradation of organic micropollutants in wastewater treatment is suspected to depend on co-degradation i.e. be dependent on concentrations of substrate. This complicates predicting and modelling their fate. The effect of humic acid, as a model for complex organic substrate, was investigated in relation to the biodegradation of pharmaceuticals by suspended biofilm carriers adapted to polishing effluent water from a tertiary sewage treatment plant. Twelve out of 22 investigated pharmaceuticals were significantly biodegradable. The biodegradation rate constants of ten of those compounds were increasing with increased humic acid concentrations. At the highest humic acid concentration $(30 \mathrm{mgC} / \mathrm{L})$, the biodegradation rate constants were four times higher than the biodegradation rate constants without added humic acid. This shows that the presence of complex substrate stimulates degradation via a co-metabolism-like mechanism and competitive inhibition does not occur. Increases of rate constant per $\mathrm{mgC} / \mathrm{L}$ are tentatively calculated.

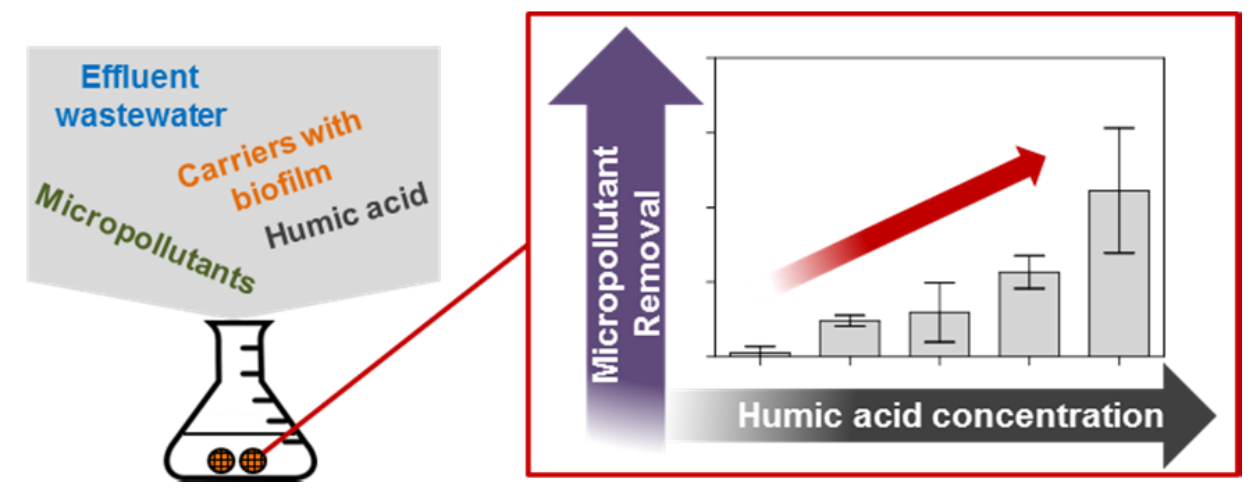

Keywords: Moving bed biofilm reactor, co-metabolism, biodegradation, dissolved organic carbon, humic acid

\section{Introduction}

Effluents from municipal wastewater treatment plants (WWTPs) contain pharmaceuticals (typically $\mu \mathrm{g} / \mathrm{L}$ ), as many of these compounds are not removed in traditional wastewater treatment processes (Falås et al., 2012a; Wang et al., 2015). As pharmaceuticals are designed to have biological effects, it is inevitable that they can 
potentially have effects on aquatic life, and thus regulation authorities increasingly develop water quality criteria for pharmaceuticals in the $\mathrm{ng} / \mathrm{L}$ and $\mu \mathrm{g} / \mathrm{L}$ ranges, which is not achievable with currently used wastewater treatment methods (Álvarez-Muñoz et al., 2015). Therefore, there is of increasing interest to understand the mechanisms of the removal of pharmaceuticals in the wastewater treatment processes and identify technologies that can achieve better removal.

Besides chemical methods for polishing pharmaceuticals in wastewater effluents such as ozonation (Hansen et al., 2016), biofilm methods are being investigated as methods to improve removal of pharmaceuticals from wastewater (Escolà Casas et al., 2015; Falås et al., 2013, 2012b; Joss et al., 2004). The moving bed biofilm reactor (MBBR) consists of a wastewater reactor containing suspended plastic carriers that serve as support to biofilm growth, making it possible to utilise the whole tank volume for biomass growth (Ødegaard, 2006). Over the past decades, MBBR have been used successfully to treat different types of wastewater containing organic chemicals of concern (Borghei and Hosseini, 2004; Chen et al., 2007; Escolà Casas et al., 2015). Previous studies have already demonstrated that MBBR reactors achieve similar or better biodegradation efficiencies for micropollutants compared to activated sludge treatment.(Escolà Casas et al., 2015; Falås et al., 2012b; Mazioti et al., 2015)

Biomass communities found in wastewater treatment facilities are related to the conditions under which they grow (Cydzik-Kwiatkowska and Zielińska, 2016). An important parameter for these conditions is the type and concentration of carbon in wastewater. However, there is a lack of knowledge on how this parameter affects biofilm activity. Biodegradation of micropollutants may interact with organic matter by two types of mechanisms: co-metabolism and competitive inhibition. The terms 'co- 
metabolism' and 'competitive inhibition' will be used in this article as defined below because they were found to be the most suitable. It is important to notice that such terms do not exactly correspond to their definition in biochemistry.

Co-metabolism involves the transformation of a non-growth substrate (pharmaceutical) in the obligate presence of a substrate that is utilised by the biomass for growth. Nongrowth substrate refers to compounds that are unable to support cell replication at the given concentrations (Dalton et al., 1982), such as micropollutants in realistic wastewater conditions. Namely, the obligatory presence of a growth substrate or another utilisable compound is essential to the main biomass and induces enzymes for assimilation or co-factors for biodegradation (Arp et al., 2001). Some relevant studies in the literature have found that phenol and glucose act as primary growth substrates and enhance the biodegradation of 4-chlorophenol, which is considered a non-growth substrate at low concentrations (Tobajas et al., 2012). Essentially under such conditions the higher the substrate concentration, the faster the degradation of the pollutant.

Competitive inhibition proposes that, a pollutant and the usual grow substrate compete for active sites (e.g. of enzymes) for being processed. Thus the higher the substrate concentration the slower the degradation of the pollutant (Chang and Alvarez-Cohen, 1995). To minimise and optimise the discrepancy between the observed removal and estimated removal of micropollutants, previous studies in the literature demonstrate that the ability of the model used to predict micro-pollutant degradation improved after the addition of an parameter regarding competitive inhibition (Plósz et al., 2010). Experimentally, Joss et al. (2004) found that differences in the removal rates of oestrogens, between the batch experiment and the corresponding compartment of fullscale plants, could be interpreted in terms of the competitive inhibition of oestrogen 
degradation by the substrate. This was explained because the batch experiments were run without adding a primary effluent, while the full-scale plants were operated under regular conditions (Joss et al., 2004).

According to the descriptions above, co-metabolism and competitive inhibition thus make opposite predictions on the effect of substrate on pollutant removal.

The aim of this study was to investigate the effect of additional carbon sources on the removal of micropollutants by biofilms. Specifically, laboratory-scale MBBRs were used to mimic a potential treatment for effluent wastewater from a CAS treatment plant. In this test, humic acid (HA) was chosen to simulate different concentrations of complex carbon (i.e. not easily biodegradable carbon) as a carbon source (feed) to induce biological activity. This way it was tested whether enhanced carbon loads are beneficial or detrimental to degradation of recalcitrant compounds (meaning whether the effect of co-metabolism or competitive inhibition by additional carbon is predominant).

\section{Methods}

\subsection{Chemicals}

The investigated micropollutants include antibiotics (azithromycin, ciprofloxacin, sulfadiazine, sulfamethizole, sulfamethoxazole, trimethoprim and the sulfadiazine metabolite acetyl-sulfadiazine), beta-blockers (atenolol, metoprolol, propranolol and sotalol), antindepressants/antiepileptics (venlafaxine and carbamazepine), analgesics (diclofenac, ibuprofen, phenazone and tramadol) and X-ray contrast media (iopromide, iohexol and iopamidol). The investigated compounds were obtained from different suppliers, as described in the supplementary information (SI; Table S1). Formic acid 
and gradient-grade methanol were obtained from Merck (Darmstadt, Germany). Humic acid sodium salt was purchased from Sigma-Aldrich (Steinheim, Germany), and water of a gradient grade came from Sigma-Aldrich (Munich, Germany).

\subsection{Instruments}

The HPLC was equipped with a dual low-pressure mixing ternary gradient system, namely Ultimate 3000, from Dionex. This system consisted of a pump, a column oven and a degasser, which were all 3000 series, and a 3000 TSL autosampler (WPS 3000 TSL). The mass spectrometer was an API 4000 (ABSciex, Framingham, MA, USA). The HPLC-MS/MS conditions are the same as the supplementary information (S2) in Escolà Casas et al. (2015).

\subsection{Wastewater and the growth of biofilm carriers}

The effluent wastewater used for the growth of the biofilm carriers and for the experiment was collected from Bjergmarken WWTP in Roskilde, Denmark. Bjergmarken WWTP is a classical activated sludge plant, with nitrification and denitrification as well as biological phosphorus removal. The wastewater was stored at $4^{\circ} \mathrm{C}$ and before starting the experiment it was allowed to reach room temperature. The characteristics of the wastewater in this experiment are presented in Table S2.

To grow the biofilm on the carriers, 150 new MBBR-carriers K5 $\left(800 \mathrm{~m}^{2} / \mathrm{m}^{3}\right.$ specific surface area) from AnoxKaldnes ${ }^{\mathrm{TM}}$ (AnoxKaldnes, Lund, Sweden) were incubated in a beaker containing $1500 \mathrm{~mL}$ of the described effluent wastewater. The carriers were stirred with a magnetic stir-bar and the wastewater was fully changed three times a week. No additional aeration was performed, as oxygen consumption in the system was very low. These conditions were maintained for four months. At that time, the carriers were ready for the batch experiment. 


\subsection{Experimental design and procedure}

The experiment consisted in testing the degradation of spiked pharmaceuticals in secondary treated wastewater in the presence of three defined concentrations of humic acid (all in triplicates). Humic acid sodium salt was used in this experiment, as it is easier to solubilise than natural, isolated humic acid. To prepare solutions of humic acid 4.9, 7.4 or $24.7 \mathrm{mg}$ humic acid sodium salt were added into $200 \mathrm{~mL}$ volumetric flasks which were filled with effluent from Bjergmarken WWTP.

For the spiking, $10 \mu \mathrm{L}$ of a stock solution containing pharmaceuticals in methanol were transferred to $100 \mathrm{~mL}$ Erlenmeyer flasks. After the methanol had evaporated, $40 \mathrm{~mL}$ of the previous humic acid sodium salt solutions in effluent water were introduced into the respective flasks. This gave initial concentrations of the pharmaceuticals ranging between 1.2 and $14.6 \mu \mathrm{g} / \mathrm{L}$.

When the flasks were prepared, three carriers with biofilm were placed into each of them. This resulted in a filling ratio of $23 \%$, corresponding to $104 \mathrm{~m}^{2} / \mathrm{m}^{3}$ surface area, which was kept constant (maximum variations of $\pm 3 \%$ ) by adjusting the number of carriers to the remaining water at certain time-points after sampling. The experiment was more optimised for gaining comparable and stable results than for working at optimal filling ratio. The Erlenmeyer flasks were placed on a mechanical shaker (120 rpm) for a period of two weeks. The design of the experiment is shown in Table S3.

\subsection{Quantification and analysis}

\subsubsection{General parameters}

Dissolved oxygen and $\mathrm{pH}$ were measured with a multi-parameter meter (Multi 3420, WTW), while dissolved organic carbon (DOC) concentration was analysed by a total organic carbon analyser (Shimadzu, TOC-V wp with ASI-V, Japan). COD and other 
parameters mentioned for wastewater in the effluent from Bjergmarken WWTP (Table S2) were measured following Danish Standard Methods (http://www.ds.dk/en, accessed June 2015).

Biomass on the MBBR carriers was determined by using a digital balance (Sartorius Basic, BP 210D) and a drying oven (SalvisLab Thermocenter, TC40). To do so, two carriers from each flask, and new carriers without biofilm, were placed in an aluminium foil cup, dried overnight at $105^{\circ} \mathrm{C}$ and then weighed. Differences in weight between the new carriers and carriers with biofilm coverage were used as the dry biomass content.

\subsubsection{Pharmaceuticals analysis}

For the analysis of pharmaceuticals, for each time-point and flask, $1 \mathrm{~mL}$ of water was taken with an Eppendorf pipette and directly put into HPLC vials. The samples were immediately stored at $-20^{\circ} \mathrm{C}$. Before analysis they were brought up to room temperature and centrifuged for $10 \mathrm{~min}$ at $6000 \mathrm{rpm}$. Afterwards, $900 \mu \mathrm{L}$ of the supernatant were transferred to a new HPLC vial by using a glass syringe. Subsequently, $100 \mu \mathrm{L}$ of internal standard solution (sulfadiazine ${ }^{13} \mathrm{C}_{6}$; trimethoprim $\mathrm{D}_{3}$; ac-sulfadiazine ${ }^{13} \mathrm{C}_{6}$; ciprofloxacin $\mathrm{D}_{8}$; clindamycin $\mathrm{D}_{3}$; citalopram $\mathrm{D}_{6}$; propanolol $\mathrm{D}_{7}$; $\left({ }^{13} \mathrm{C}_{1}, \mathrm{D}_{3} \mathrm{~N}\right.$-methyl)erythromycin; ibuprofen $\mathrm{D}_{3}$ ) were added to each sample, using again a glass syringe. Finally, $50 \mu \mathrm{L}$ of the prepared samples were injected and analysed by means of HPLC$\mathrm{MS} / \mathrm{MS}$

\subsubsection{Data treatment}

Quantification was done via Analyst 1.6. After quantification, all of the concentrations were fitted with single first-order degradation kinetics (Equation 1) by means of Graphpad Prism 5.0. In equation $1, \mathrm{C}_{0}$ is the initial concentration of each 
pharmaceutical while $\mathrm{C}$ is the actual concentration of each pharmaceutical with time. One degradation rate constant $(\mathrm{k})$ was assumed to be valid over the entire period.

$$
C=C_{0} \cdot e^{-k t}
$$

(Equation 1)

\section{Results and discussion}

\subsection{General parameters}

The initial $\mathrm{pH}$ values of the reactors increased slightly in correspondence with increasing concentrations of added humic acid sodium salt, which is consistent with the fact that salt is alkaline. The $\mathrm{pH}$ increased further during the experiment, which could be explained by the mineralization of the humic acid that would leave an equivalent amount of alkalinity (Table 1).

The biomass on the carriers was calculated to correspond to $2.5 \mathrm{~g}$ of dry matter per litre (33 mg/carrier). The quantified biomass was lower in this work than in previous studies, which quantified 3.1 to $3.2 \mathrm{~g}$ of dry matter per litre ((Escola Casas et al. (2015); Falås et al. (2013)), indicating a possible lower bioactivity than in previous studies. A reason for that is that the biofilm in the present study was cultured on wastewater treatment plant effluent, which contained considerable lower organic matter concentrations than the MBBR reactors in literature working on wastewater. Furthermore, the carriers filling ratio of this study (23\%) was also lower than both values from Escola Casas et al. (2015) with $50 \%$ and Falås et al. (2013) with $35 \%$ which was fine for a mechanistic study such as this experiment.

Measured initial DOCs agreed with nominal concentrations calculated by measuring the background DOC in the wastewater and the organic carbon content in the humic acid salt $(0.32 \mathrm{mgC} / \mathrm{mg}$ humic acid $)$. The DOC of the control flask (C) and the flask without the addition of humic acid $\left(\mathrm{HA}_{0}\right)$ increased during the two weeks of the experiment. 
This could have been a consequence of the sampling procedure, which might have added impurities to the samples. On the contrary, the flasks spiked with humic acid exhibited decreasing DOC during the experiment, which is most likely because of the humic acid mineralisation, as also suggested from the increasing $\mathrm{pH}$. In this case, the decrease of DOC due to mineralisation could have over-compensated the increase of DOC due to the sampling. Interestingly, the DOC in the flask spiked with the highest amount of humic acid was observed to decrease proportionally much more than the flasks spiked with lower levels of humic acid. As it might be expected that the biodegradable fraction of the humic acid is constant it could be expected that some of it, due to the higher concentration and $\mathrm{pH}$, precipitated on the glass or aggregated to smaller particles which were not measured in the DOC analysis.

\subsection{Removal of pharmaceuticals}

The removal of pharmaceuticals was assessed by measuring the concentrations of the pharmaceuticals during the experiment. To do so, the concentrations of pharmaceuticals were plotted vs time. The data were fitted, when possible, to single first-order degradation kinetics as explained in Section 2.5.3. The measurements and fittings can be seen in Figure 1 for six representative compounds and in Figure S1 in the SI for the rest of compounds.

13 out of 22 compounds were biodegraded by the biofilm. This could be confirmed because the control flasks showed much slower removal than the test flasks (mediated by biomass suspended in water). Single first-order kinetics could be fitted with $\mathrm{R}^{2}$ higher than 0.8 for these 13 compounds. The removal rate constants (k from Equation 1) for the different additions of humic acid (Figure 2 and Table 2) were used to further 
investigate the effect of humic acid on the biodegradation of pharmaceuticals (Section 3.3). It was known that diclofenac was one of the most persistent compounds, and its rate constant in this study was also lower than most of the investigated compounds. Tran et al. (2009) investigated that the biodegradation of ten pharmaceuticals by an enriched nitrifier culture and found poor biodegradation removal of compounds containing at least one chlorine group in the molecular structure, such as clofibric acid and diclofenac. In this case, the chemical structure may hinder biotransformation processes.

The biofilm on the carriers was not able to degrade 9 out of 22. Some compounds presented no significant removal in both, controls and test flasks (phenanzone, sulfadiazine, sulfamethoxazole, tramadol and venlafaxine) (Figure S1). This indicated that those compounds were not degradable under the test conditions (test flasks). Other compounds showed removal rates that were significant but not statistically different from the control (azithromycin, clarithromycin, erythromycin, roxithromycin). For these compounds degradation in the control reactor was detected. This might be due to either biodegradation by bacteria present in the effluent wastewater in suspension or abiotic reactions. Furthermore, hydrolysis or photolysis might lead to slightly reduce the concentrations of pharmaceuticals as well. In this case, even if the compounds were degradable in the test conditions, it was thus not possible to distinguish between the removal by suspended bacteria and the removal mediated by the biofilm. Therefore the effect of the humic acid addition was not assessed for these nine compounds.

In order to make the results comparable with other studies in the literature, the removal rate constants $(\mathrm{k})$ were normalized to the biomass content of the carriers $\left(\mathrm{k}_{\mathrm{bio}}\left[\mathrm{h}^{-1} \cdot \mathrm{L} \cdot \mathrm{g}^{-1}\right]\right)$. Compared to previous investigations on the degradation of pharmaceuticals by MBBR, 
the $\mathrm{k}_{\text {bio }}$ values in this work are ten to hundred times lower (Table S4) than those described for the same pharmaceuticals by Escolà Casas et al. (2015) and Falås et al. (2013). An explanation for this might be that the biofilm investigated in this study was grown as polishing reactor in effluent wastewater and it was thus acclimatised to lower C loads. Therefore, the biofilm was probably adapted to slow metabolism as an adaptation to the low-nutrient environment.

\subsection{Influence of humic acid on pharmaceutical degradation}

Considering the removal rate constants of the 13 pharmaceuticals which exhibited biodegradation, it is clear that increasing the DOC by adding humic acid affected the degradation kinetic of pharmaceuticals. To create an overview of the influence of the initial DOC on the kinetic of pharmaceutical biodegradation, degradation rate constants of the six representative compounds are shown in Figure 2 (all pharmaceuticals are shown in Figure S2).

All the biodegradable pharmaceuticals appeared to degrade faster in test flasks with increased humic acid concentration. Regarding the mentioned theories on the interaction of organic carbon with biodegradation (Section 1), it thus appears that increased "cometabolism" is the main effect of increased humic acid concentration for the studied compounds. Competitive inhibition appears not to be relevant for humic acid interactions with the biodegradation of pharmaceuticals. Furthermore, based on the low COD values of the wastewater (described in Table S2) and continuous shaking during the experiment (dissolved oxygen measured at $8 \mathrm{mg} / \mathrm{L}$ ), co-metabolic degradation of pharmaceuticals occurred. This means that pharmaceuticals were oxidised by an 
enzyme or co-factor produced during the microbial metabolism of another growth substrate with oxygen (Tran et al., 2013).

\subsection{Relationship between total concentration of organic matter and rate constant}

The relation between $\mathrm{k}$ and the initial DOCs for the biodegradable pharmaceuticals was plotted and it is shown in Figure 3 and Table 2. According to the fittings, the slopes of 10 out of 13 compounds are positive, which suggest that the addition of humic acid stimulates the biodegradation of pharmaceuticals in biofilms. Based on the slope, the effect of initial DOC on $\mathrm{k}$ could be stated to be stimulated from $-0.6 \%$ to $26 \%$ per $\mathrm{mgC} / \mathrm{L}$. The average stimulation of for all biodegradable pharmaceuticals was $7.4 \%$ per $\mathrm{mgC} / \mathrm{L}$ and the $25 \%, 50 \%$ and $75 \%$ percentiles were $2.8,6.4$ and $8.7 \%$ per $\mathrm{mgC} / \mathrm{L}$, respectively. As the effect of DOC for half of the biodegradable compounds fall in a relatively narrow range we propose that this can be used as a default value in modelling the effect of increased DOC in a WWTP in cases there a specific value isn't known for a pharmaceutical.

As results in Figure 3, the flasks containing the highest level of DOC (initially 30 $\mathrm{mgC} / \mathrm{L}$ ) gave rate constant double or triple the values obtained for the flasks without addition of humic acid (initially $4.4 \mathrm{mgC} / \mathrm{L}$ ). Taking this into account, it seems that the addition of carbon can enhance the efficiency of MBBR reactors. Therefore, further studies with more concentration levels should be done to establish precise correlations between the levels of DOC and the removal of pharmaceuticals in water.

\section{Conclusion}

Generally, the majority of biodegradable pharmaceuticals degraded faster at higher DOC levels. This indicates that co-metabolism may be the most important mechanism 
when humic acids interact with the degradation of pharmaceuticals. The average stimulation of the first-order degradation rate for biodegradable pharmaceuticals was 5\% per mg DOC. 30 $\mathrm{mgC} / \mathrm{L}$ by humic acid addition enhanced about three times the biodegradation performance of the laboratory-scale MBBRs.

\section{Acknowledgments}

The authors acknowledge funding to the MERMISS project (Miljøeffektiv rensning af højpotente lægemiddelstoffer i hospitalsspildevand/Environmentally effective removal of pharmaceuticals from hospital wastewater) from the MUDP program by the Danish Ministry of the Environment and funding from the AUFF grant "Advanced water purification using bio-inorganic nanocatalysts and soil filters" (http://waterpurification.au.dk/).

\section{References}

Álvarez-Muñoz, D., Rodríguez-Mozaz, S., Maulvault, A.L., Tediosi, A., FernándezTejedor, M., Van den Heuvel, F., Kotterman, M., Marques, A., Barceló, D., 2015. Occurrence of pharmaceuticals and endocrine disrupting compounds in macroalgaes, bivalves, and fish from coastal areas in Europe. Environ. Res. 143, 56-64. doi:10.1016/j.envres.2015.09.018

Arp, D.J., Yeager, C.M., Hyman, M.R., 2001. Molecular and cellular fundamentals of aerobic cometabolism of trichloroethylene. Biodegradation 12, 81-103. doi:10.1023/A:1012089908518

Borghei, S.M., Hosseini, S.H., 2004. The treatment of phenolic wastewater using a moving bed biofilm reactor. Process Biochem. 39, 1177-1181. doi:10.1016/S00329592(02)00195-4

Chang, H.L., Alvarez-Cohen, L., 1995. Transformation capacities of chlorinated organics by mixed cultures enriched on methane, propane, toluene, or phenol. Biotechnol. Bioeng. 45, 440-449. doi:10.1002/bit.260450509

Chen, S., Sun, D., Chung, J.S., 2007. Treatment of pesticide wastewater by moving-bed biofilm reactor combined with Fenton-coagulation pretreatment. J. Hazard. Mater. 144, 577-584. doi:10.1016/j.jhazmat.2006.10.075

Dalton, H., Stirling, D.I., Quayle, J.R., 1982. Co-Metabolism [and Discussion]. Philos. Trans. R. Soc. B Biol. Sci. 297, 481-496. doi:10.1098/rstb.1982.0056

Escolà Casas, M., Chhetri, R.K., Ooi, G., Hansen, K.M.S., Litty, K., Christensson, M., 
Kragelund, C., Andersen, H.R., Bester, K., 2015. Biodegradation of pharmaceuticals in hospital wastewater by staged Moving Bed Biofilm Reactors (MBBR). Water Res. 83, 293-302. doi:10.1016/j.watres.2015.06.042

Falås, P., Andersen, H.R., Ledin, A., Jansen, J. la C., 2012a. Occurrence and reduction of pharmaceuticals in the water phase at Swedish wastewater treatment plants. Water Sci. Technol. 66, 783. doi:10.2166/wst.2012.243

Falås, P., Baillon-Dhumez, A., Andersen, H.R., Ledin, A., la Cour Jansen, J., 2012 b. Suspended biofilm carrier and activated sludge removal of acidic pharmaceuticals. Water Res. 46, 1167-1175. doi:10.1016/j.watres.2011.12.003

Falås, P., Longrée, P., la Cour Jansen, J., Siegrist, H., Hollender, J., Joss, A., 2013. Micropollutant removal by attached and suspended growth in a hybrid biofilmactivated sludge process. Water Res. 47, 4498-4506. doi:10.1016/j.watres.2013.05.010

Hansen, K.M.S., Spiliotopoulou, A., Chhetri, R.K., Escolà Casas, M., Bester, K., Andersen, H.R., 2016. Ozonation for source treatment of pharmaceuticals in hospital wastewater - Ozone lifetime and required ozone dose. Chem. Eng. J. 290, 507-514. doi:10.1016/j.cej.2016.01.027

Joss, A., Andersen, H., Ternes, T., Richle, P.R., Siegrist, H., 2004. Removal of estrogens in municipal wastewater treatment under aerobic and anaerobic conditions: Consequences for plant optimization. Environ. Sci. Technol. 38, 30473055. doi:10.1021/es0351488

Mazioti, A. a., Stasinakis, A.S., Pantazi, Y., Andersen, H.R., 2015. Biodegradation of benzotriazoles and hydroxy-benzothiazole in wastewater by activated sludge and moving bed biofilm reactor systems. Bioresour. Technol. 192, 627-635. doi:10.1016/j.biortech.2015.06.035

Plósz, B.G., Leknes, H., Thomas, K. V., 2010. Impacts of competitive inhibition, parent compound formation and partitioning behavior on the removal of antibiotics in municipal wastewater treatment. Environ. Sci. Technol. 44, 734-742. doi:10.1021/es902264w

Tobajas, M., Monsalvo, V.M., Mohedano, A.F., Rodriguez, J.J., 2012. Enhancement of cometabolic biodegradation of 4-chlorophenol induced with phenol and glucose as carbon sources by Comamonas testosteroni. J. Environ. Manage. 95, S116-S121. doi:10.1016/j.jenvman.2010.09.030

Tran, N.H., Urase, T., Kusakabe, O., 2009. The characteristics of enriched nitrifier culture in the degradation of selected pharmaceutically active compounds. J. Hazard. Mater. 171, 1051-1057. doi:10.1016/j.jhazmat.2009.06.114

Tran, N.H., Urase, T., Ngo, H.H., Hu, J., Ong, S.L., 2013. Insight into metabolic and cometabolic activities of autotrophic and heterotrophic microorganisms in the biodegradation of emerging trace organic contaminants. Bioresour. Technol. 146, 721-731. doi:10.1016/j.biortech.2013.07.083

Wang, Z., Zhang, X.-H., Huang, Y., Wang, H., 2015. Comprehensive evaluation of pharmaceuticals and personal care products (PPCPs) in typical highly urbanized regions across China. Environ. Pollut. 204, 223-232. doi:10.1016/j.envpol.2015.04.021 
Yao, W., Wang, X., Yang, H., Yu, G., Deng, S., Huang, J., Wang, B., Wang, Y., 2016. Removal of pharmaceuticals from secondary effluents by an electro-peroxone process. Water Res. 88, 826-835. doi:10.1016/j.watres.2015.11.024

Ødegaard, H., 2006. Innovations in wastewater treatment: The moving bed biofilm process. Water Sci. Technol. 53, 17-33. doi:10.2166/wst.2006.284 